\title{
Anxiety among Doctors during COVID-19 Pandemic in Secondary and Tertiary Care Hospitals
}

\author{
Syed Riazul Hasan', Zeeshan Hamid², \\ Muhammad Talha Jawaid ${ }^{3}$, Rashida Kaizar Ali $^{4}$
}

\begin{abstract}
Objective: To assess the level of anxiety among doctors during COVID-19 pandemic and the associated risk factors.

Methods: This cross-sectional study was conducted from 30th April to 16th May, 2020 in Karachi, Pakistan. The data was collected via an online web-based questionnaire. Questionnaire was used to assess anxiety level using GAD-7 scale among health-care professionals and the risk factors playing role in it.

Results: One hundred and fifty-one doctors participated in our study. Out of these 151 participants, 69 (45.7\%) had mild, $22(14.6 \%)$ had moderate, and $5(3.3 \%)$ had severe symptoms of anxiety, whereas the remaining $55(36.4 \%)$ had no anxiety according to GAD-7 scale. The median [interquartile range (IQR)] GAD-7 scale scores are 6.0 [3.00-9.00]. Females showed more severe degrees of measurement of anxiety symptoms than males. Doctors dealing with COVID-19 patients showed higher level of anxiety as compared to the doctors who were not dealing with COVID-19 patients, having a significant difference $(U=9.697, p=$ 0.008). One hundred and forty-one (93.4\%) participants were concerned about being exposed to COVID-19 at work and $112(74.2 \%)$ thought they have inadequate protective equipment for safety.

Conclusions: During COVID-19 pandemic, doctors exhibited different grades of anxiety. In order for healthcare workers to perform to the best of their capability, certain guidelines and interventions are needed.
\end{abstract}

KEYWORDS: COVID-19, Anxiety, GAD-7, Doctors, Pandemic.

doi: https://doi.org/10.12669/pjms.36.6.3113

How to cite this:

Hasan SR, Hamid Z, Jawaid MT, Ali RK. Anxiety among Doctors during COVID-19 Pandemic in Secondary and Tertiary Care Hospitals. Pak J Med Sci. 2020;36(6):1360-1365. doi: https://doi.org/10.12669/pjms.36.6.3113

This is an Open Access article distributed under the terms of the Creative Commons Attribution License (http://creativecommons.org/licenses/by/3.0), which permits unrestricted use, distribution, and reproduction in any medium, provided the original work is properly cited.

1. Dr. Syed Riazul Hasan, FCPS.

Head of Department,

2. Dr. Zeeshan Hamid, MBBS.

Resident Medical Officer,

3. Dr. Muhammad Talha Jawaid, MBBS.

Post-graduate Trainee,

4. Dr. Rashida Kaizar Ali, MBBS. Post-graduate Trainee,

1-4: Department of Internal Medicine, Sindh Government Qatar Hospital, Karachi, Pakistan.

Correspondence:

Dr. Syed Riazul Hasan, FCPS. Head of Department, Department of Internal Medicine,

Sindh Government Qatar Hospital,

Orangi Town, Karachi, Pakistan.

E-mail: drriaz222@yahoo.com

* Received for Publication:

June 23, 2020

* Revision Received:

* Revision Accepted:

\section{INTRODUCTION}

COVID-19, that took the world by storm, emerged as a worldwide health care crisis, resulting in the first pandemic of the 21st century. It first was reported in December 2019 to the World Health Organization as a cluster of cases of pneumonia in the city of Wuhan, China which was later identified as a novel coronavirus. ${ }^{1}$ Soon it spread to the other countries, and by 9th of August 2020, the total number of confirmed infected cases has crossed over 2.7 million, ${ }^{2}$ and the total death toll has crossed 7,22,285. ${ }^{2}$

In Pakistan, the first confirmed case was reported by the Ministry of Health, Government of Pakistan on $26^{\text {th }}$ February, 2020 in the city of Karachi, Sindh province. ${ }^{3}$ By $10^{\text {th }}$ of August, 2020, the total number of confirmed cases in Pakistan 
had reached to 284,660 with 6,097 deaths reported. ${ }^{4}$ The ever-increasing number of cases has not only created a panic among the general population but has also increased the workload on the healthcare system resulting in an add-on pressure on the health care professionals and the personnel associated with health care system including the health care administration. The overwhelming burden of the pandemic has resulted in not only the physical but psychological pressure on health care workers. This has previously been seen as deteriorating psychological impact on health care workers during the SARS outbreak in 2013. ${ }^{5}$

Knowing that this health crisis could last months, it is also essential that the health care professionals and providers are well taken care of not just physically but psychologically for them to be able to perform to their full potential. In doing that, we conducted a survey to assess the level of anxiety among health care providers and look for the factors that might be responsible for it. The study would help in building a foundation for certain guidelines to be made for the better care of the personnel associated with health care by the institution on a limited scale and by national health governing bodies on a larger scale in Pakistan.

\section{METHODS}

This cross-sectional study was conducted between 30th April, 2020 and 16th May, 2020. A total of 151 doctors working in both public and private sector hospitals in the city of Karachi to participate in this survey after taking informed consent. Study protocol was approved for data collection by the Medical Superintendent of Sindh Government Qatar Hospital, Karachi.

Ethical Approval: (Ref No: SGQH/2929, Dated: 1806-2020).

The data was collected via an online webbased questionnaire. The questionnaire included a mandatory pre-requisite informed consent. A psychiatrist working at Sindh Government Qatar Hospital, Karachi was consulted who provided his valuable input on the questionnaire. The questionnaire consisted of three parts: A) Basic demographic data which included age, gender, marital status, education level (bachelor's or master's), working as (a doctor or an administrative official), working in capacity of (administrative official not seeing patients- LEVEL ONE, health care professional seeing patients other than COVID-19LEVEL TWO, health care professionals seeing patients of suspected or confirmed COVID-19 in
Emergency Department or Isolation Ward- LEVEL THREE). B) A GAD-7 questionnaire was used to assess anxiety. GAD-7 as proposed by Spitzer RL et al. ${ }^{6}$ consists of 7 items is helpful as a screening tool for anxiety and assessing its severity in clinical practice. ${ }^{6}$ Participants were asked how often during the last two weeks; they faced the mentioned symptoms. The responses were recorded as "not at all", "several days", "more than half the days", and "nearly every day", and subsequent scores were given as $0,1,2$, and 3 respectively. The total score for the seven items ranges from 0 to 21 . At a score of 10 or more, sensitivity and specificity exceed $80 \% .^{7}$ The scores were assessed according to the following criteria: ${ }^{6,8,9}$ (5-9): mild anxiety, (10-14): moderate anxiety (15-21): severe anxiety. C) Risk factors associated with that anxiety were addressed that might be playing role in precipitating the anxiety including being exposed to COVID-19, having access to protective equipment, having access to safety precautions at workplace, concerns about family members, feeling exhaustion at work and having necessary knowledge regarding precautionary measures and COVID-19.

Statistical Analysis: Data was analyzed using IBM SPSS Statistics software (version 26). For categorical variables, the number of cases and percentages were used. The GAD-7 score was not normally distributed and hence is presented as medians with interquartile ranges (IQRs). The nonparametric tests Mann-Whitney U Test and Kruskal-Wallis Test were performed for comparing non-normally distributed continuous dependent variables with categorical independent variables. The level of significance was set as $\mathrm{p}<0.05$.

\section{RESULTS}

Out of a total of 151 doctors who participated, a total of 85 (56.3\%) were Females (Table-I). Mean age was $29( \pm 7.28)$ years, out of which majority $89(58.9 \%)$ were of age less than 29 years. A total of $76(50.3 \%)$ were not married. The other demographic data is shown in (Table-I).

Out of 151 participants, $69(45.7 \%)$ had mild, 22 $(14.6 \%)$ had moderate, and $5(3.3 \%)$ had severe symptoms of anxiety, whereas the remaining $55(36.4 \%)$ had GAD-7 scale score of less than 5, which is considered normal or healthy level of anxiety. The original scores of GAD-7 tool were not normally distributed and so are presented as Medians with interquartile ranges (IQRs). Out of a total of 151 participants, the median [interquartile range (IQR)] GAD-7 scale scores is 6.0 [3.00-9.00]. 
Table-I: Demographic Characteristics of Participants.

\begin{tabular}{|c|c|c|c|}
\hline Characteristic & $N(\%)$ & & Total N \\
\hline \multirow[t]{2}{*}{ Gender } & Male & $66(43.7 \%)$ & 151 \\
\hline & Female & $85(56.3 \%)$ & \\
\hline \multirow[t]{4}{*}{ Age } & $18-29$ years & $89(58.9)$ & 151 \\
\hline & $30-39$ years & $50(33.1 \%)$ & \\
\hline & $40-49$ years & $10(6.6 \%)$ & \\
\hline & Above 50 years & $2(1.3 \%)$ & \\
\hline \multirow[t]{2}{*}{ Marital Status } & Single & $76(50.3 \%)$ & 151 \\
\hline & Married & $75(49.7 \%)$ & \\
\hline \multirow[t]{2}{*}{ Education } & MBBS & $115(76.2 \%)$ & 151 \\
\hline & Post-graduation (FCPS) & $36(23.8 \%)$ & \\
\hline \multirow[t]{2}{*}{ Institution } & Public sector hospital & $106(70.2 \%)$ & 151 \\
\hline & Private sector hospital & $45(29.8 \%)$ & \\
\hline \multirow[t]{3}{*}{$\begin{array}{l}\text { Working In } \\
\text { Capacity of }\end{array}$} & $\begin{array}{l}\text { Doctors working as administrative officials not dealing with } \\
\text { patients directly (Level-1, at low risk) }\end{array}$ & $20(13.2 \%)$ & 151 \\
\hline & Doctors seeing patients other than COVID-19 (Level-2, at medium risk) & $90(59.6 \%)$ & \\
\hline & $\begin{array}{l}\text { Doctors seeing patients of suspected or confirmed COVID-19 } \\
\text { in Emergency Department or Isolation Ward (Level-3, at high risk) }\end{array}$ & $41(27.2 \%)$ & \\
\hline
\end{tabular}

A Mann-Whitney $U$ test showed that there was a significant difference $(U=4004, p<0.001)$ between the GAD-7 scores for males compared to females. Females showed more severe degrees of measurement of anxiety symptoms than males, as median [interquartile range (IQR)] GAD-7 scale scores among males versus females: 4.0 [2.0-7.0] versus 8.0 [5.0-9.0]; $[\mathrm{p}<0.001]$. The comparison of the

Table-II: Gad-7 Anxiety Scores Assessment and Comparison between Groups.

\begin{tabular}{|c|c|c|c|c|c|}
\hline Components & & $\begin{array}{c}\text { Total } \\
\text { Participants } \\
N=151(\%)\end{array}$ & $\begin{array}{l}\text { Median and } 1 \\
\text { Interquartile } \\
\text { Range (IQR) } \\
\text { for GAD-7 Score }\end{array}$ & $\begin{array}{l}\text { Mann-Whitney } \\
\text { U test and } \\
\text { P value }\end{array}$ & $\begin{array}{l}\text { yStatistically Significant }(P<.05) \\
\text { Interpretation }\end{array}$ \\
\hline \multirow{4}{*}{$\begin{array}{c}\text { Level of } \\
\text { Anxiety }\end{array}$} & Normal & $55(36.4 \%)$ & \multirow{4}{*}{$6.0[3.0-9.0]$} & \multirow{4}{*}{---} & \multirow{4}{*}{--- } \\
\hline & Mild & $69(45.7 \%)$ & & & \\
\hline & Moderate & $22(14.6 \%)$ & & & \\
\hline & Severe & $5(3.3 \%)$ & & & \\
\hline \multirow{2}{*}{$\begin{array}{l}\text { Gender } \\
\text { Difference }\end{array}$} & Male & $66(43.7 \%)$ & $4.0[2.0-7.0]$ & \multirow{4}{*}{$\begin{array}{l}(\mathrm{U}=4004 \\
\mathrm{P}<0.001) \\
(\mathrm{U}=3013 \\
\mathrm{P}=.543)\end{array}$} & \multirow{4}{*}{$\begin{array}{l}\text { Females showed more severe degrees of } \\
\text { measurement of anxiety symptoms than males. } \\
\text { There was not a significant difference between } \\
\text { the GAD-7 scores for single compared to } \\
\text { married participants. }\end{array}$} \\
\hline & Female & $85(56.3 \%)$ & $8.0[5.0-9.0]$ & & \\
\hline \multirow{2}{*}{$\begin{array}{l}\text { Marital Status } \\
\text { Difference }\end{array}$} & Single & $76(50.3 \%)$ & $6.0[3.0-9.0]$ & & \\
\hline & Married & $75(49.7 \%)$ & $7.0[4.0-9.0]$ & & \\
\hline Education & MBBS & $115(76.2 \%)$ & $7.00[4.0-9.0]$ & \multirow{2}{*}{$\begin{array}{c}(\mathrm{U}=1948.5 \\
\mathrm{P}=.594)\end{array}$} & \multirow{2}{*}{$\begin{array}{l}\text { There was not a significant difference between } \\
\text { the GAD-7 scores for doctors having only MBBS } \\
\text { degree compared to doctors having Post- } \\
\text { graduation degree. }\end{array}$} \\
\hline Difference & $\begin{array}{l}\text { Post- } \\
\text { graduation }\end{array}$ & $36(23.8 \%)$ & $5.50[3.0-9.0]$ & & \\
\hline Institution & Public sector & $106(70.2 \%)$ & $7.00[3.0-9.0]$ & \multirow{2}{*}{$\begin{array}{c}(\mathrm{U}=2149.0 \\
\mathrm{P}=.335)\end{array}$} & \multirow{2}{*}{$\begin{array}{l}\text { There was not a significant difference between } \\
\text { the GAD-7 scores for doctors working in public } \\
\text { compared to private sector. }\end{array}$} \\
\hline Difference & Private sector & $45(29.8 \%)$ & $5.00[4.0-8.0]$ & & \\
\hline High Risk & Level-3 & $41(27.2 \%)$ & $8.0[4.0-11.0]$ & \multirow{4}{*}{$\begin{array}{c}(\mathrm{U}=9.697 \\
\mathrm{P}=.008)^{*}\end{array}$} & \multirow{4}{*}{$\begin{array}{l}\text { LEVEL-3 (at high risk exposure) doctors dealing } \\
\text { with suspected or confirmed COVID-19 patients } \\
\text { showed more severe anxiety symptoms than } \\
\text { doctors not dealing with COVID-19 patients } \\
\text { directly. }\end{array}$} \\
\hline Exposure to & Level-2 & $90(59.6 \%)$ & $6.0[2.0-8.0]$ & & \\
\hline Medium and & Level-1 & $20(13.2 \%)$ & $5.0[3.5-7.5]$ & & \\
\hline \multicolumn{4}{|c|}{ Low Risk Exposure Difference } & & \\
\hline
\end{tabular}

*A Kruskal-Wallis Test was used for statistical difference between the GAD-7 scores for the group of LEVEL-3 (at high risk exposure) compared to the groups of LEVEL-2 (at medium risk exposure) and LEVEL-1 (at low risk exposure) doctors. 
Table-III: Risk Factors Association.

\begin{tabular}{lccc}
\hline FACTORS & \multicolumn{2}{c}{ Total Participants N=151(\%) } \\
\hline & Yes & No & OPT Not to Answer \\
\hline Concerned about being exposed to COVID-19 at work & $141(93.4 \%)$ & $9(1.0 \%)$ & $1(0.7 \%)$ \\
Inadequate protective equipment for safety & $112(74.2 \%)$ & $37(24.5 \%)$ & $2(1.3 \%)$ \\
Fear of taking the infection to loved ones at home & $147(97.4 \%)$ & $3(2.0 \%)$ & $1(0.7 \%)$ \\
Doubtful about working in a pandemic & $88(58.3 \%)$ & $56(37.1 \%)$ & $7(4.6 \%)$ \\
Concerned about having access to testing facilities if they develop & $95(62.9 \%)$ & $52(34.4 \%)$ & $4(2.6 \%)$ \\
$\quad$ COVID-19 symptoms & $121(80.1 \%)$ & $27(17.9 \%)$ & $3(2.0 \%)$ \\
Concerned about being up-to-date of knowledge on dealing & & & \\
$\quad$ with COVID-19 patients & $107(70.9 \%)$ & $33(21.9 \%)$ & $11(7.3 \%)$ \\
Concerned if their organization will take care of their families in case & & \\
$\quad$ they get infected with COVID-19 while working during a pandemic & & & \\
Concerned about being able to perform to the best of their ability if & $119(78.8 \%)$ & $24(15.9 \%)$ & $8(5.3 \%)$ \\
$\quad$ transferred to a new facility during pandemic & & & \\
Concerned about having access to soap with water and/or hand & $96(63.6 \%)$ & $54(35.8 \%)$ & $1(0.7 \%)$ \\
$\quad$ sanitizer at workplace & & & \\
Anticipation of feeling exhausted while working & $113(74.8 \%)$ & $36(23.8 \%)$ & $2(1.3 \%)$ \\
Fear of being isolated in case they develop COVID-19 symptoms & $120(79.5 \%)$ & $29(19.2 \%)$ & $2(1.3 \%)$ \\
National duty to work during a pandemic & $112(74.2 \%)$ & $25(16.6 \%)$ & $14(9.3 \%)$ \\
\hline
\end{tabular}

distribution of GAD-7 scores between the different categories of marital status, education, institution, and level of exposure is shown in (Table-II).

Out of a total of 151 participants, $45(29.8 \%)$ had access to surgical mask; latex or plastic gloves only, $9(6.0 \%)$ had access to surgical mask only, $2(1.3 \%)$ had access to latex or plastic gloves only, $4(2.6 \%)$ had no access to protective equipment, 17 (11.2\%) had access to surgical mask; N-95 respirator; latex or plastic gloves; surgical cap; goggles; face shield; personal protective gown, $14(9.3 \%)$ had access to surgical mask; N-95 respirator; latex or plastic gloves, the others $(39.8 \%)$ had different combinations of equipment.

Out of a total of 151 participants, 141 (93.4\%) were concerned about being exposed to COVID-19 at work. Twenty-two (14.6\%) had infants less than one year of age at home, $56(37.1 \%)$ had adults above 60 years of age, $40(26.5 \%)$ had both infants and adults, and $33(21.9 \%)$ did not have either infants or adults. The other possible factors precipitating anxiety are shown in (Table-III).

\section{DISCUSSION}

The health care professionals in general, and the front-line health care workers dealing with COVID-19 patients directly in specific, are facing a situation that they were never prepared for. The physical over-burden along with the psychological impact of such a pandemic has resulted in increased anxiety among the health care workers. In our study, we assessed anxiety among doctors and the associated risk factors during COVID-19.

A cross-sectional study done in China where they addressed factors associated with mental health outcomes among health care workers, in which they used the 7-item Generalized Anxiety Disorder scale, showed that $44.6 \%$ participants had symptoms of anxiety. ${ }^{7}$ The cutoff score they used for detecting symptoms of anxiety using GAD7 was 7 and participants who had scores greater than the cutoff threshold were characterized as having severe symptoms. ${ }^{7}$ In our study, we focused on anxiety and also used the 7-item Generalized Anxiety Disorder (GAD-7) for assessing anxiety.

In our study, out of a total of 151 participants, 69 $(45.7 \%)$ had mild, 22 (14.6\%) had moderate, and 5 (3.3\%) had severe symptoms of anxiety. ${ }^{6,8,9}$ A total of $56.3 \%$ participants were predominantly females, which is comparable to the study done in China which also had a female $(76.7 \%)$ predominance. ${ }^{7}$ The median [Interquartile range(IQR)] for GAD-7 scores in our study for males versus females: 4.0 [2.0-7.0] versus 8.0 [5.0-9.0] showing females had more severe degrees of measurement of anxiety symptoms than males, which was again similar to the study in China which had the median [Interquartile range(IQR)] for GAD-7 for males versus females: 2.0 [0-6.0] versus 4.0 [1.0-7.0]. ${ }^{7}$ In our study, Level-3 (at high risk exposure) doctors who were dealing with suspected or confirmed COVID-19 patients had higher GAD-7 median 
scores compared to Level-2 (at medium risk exposure) and Level-1 (at low risk exposure) doctors, which was again similar to the study in China which showed frontline health care workers diagnosing and treating COVID-19 patients were associated with high risk of anxiety symptoms. ${ }^{7}$

Another study done in Singapore during COVID-19 pandemic in which they used Depression, Anxiety, and Stress Scales (DASS-21) to assess overall mental status showed that $14.5 \%$ participants screened positive for anxiety, ${ }^{10}$ whereas in our study, we used GAD-7 to assess anxiety and results showed 27 (17.9\%) participants had moderatesevere anxiety. Another study done in Peshawar city of Pakistan during March-April 2020 which assessed the personal and professional impact of COVID-19 on health care professionals..$^{11}$ It was a qualitative study and showed that the participants felt anxious, frustrated and stressed out. This study had participants mostly females (56.5\%) similar to our study having females $(56.3 \%)$ predominant.

While the COVID-19 situation in hand is unexpected, and perhaps not well prepared for, drastic measures need to be taken and ensured in order to maximize the workforce that is available. The first and foremost consideration in this regard is communicating with the health care workers by the organization, especially the hospital leadership along with professional psychologists. Actively communicating with the health care workers is the key in reducing anxiety. Out of a total of 151 participants, $121(80.1 \%)$ were concerned about being up-to-date of knowledge on dealing with COVID-19 patients, 27 (17.9\%) said they were upto-date of knowledge on dealing with COVID-19 patients, and $3(2.0 \%)$ opted not to answer. Special emphasis should be given on guidelines for protecting themselves, their family members, dealing with the patients, keeping up-to-date about knowledge regarding COVID-19, and any individual concerns.

The patients might not be suspected of having COVID-19, but they might be asymptomatic and yet transmitting the disease ${ }^{12}$, hence precautionary measures need to be taken. Letting the health care workers know that their safety is of priority focus for the organization. Overall, $112(74.2 \%)$ participants thought they have inadequate protective equipment for safety from COVID-19. Knowing that protective equipment is critically short in such times of crisis, health care professionals such as administrative officials should have access to face surgical masks at the least, doctors who deal with patients other than COVID-19 should have access to face surgical masks, plastic or latex gloves, and goggles (in case dealing with patients with possible respiratory illness) ${ }^{13}$, and doctors who deal with suspected or confirmed COVID-19 patients should have access to N-95 respirator, latex gloves, surgical cap, goggles or face shield along with personal protective gown.

Along with the protective gear, the health care workers need access to water with soap and sanitizers at their workplace. It has been an established fact that the COVID-19 virus can live on surfaces for hours or possibly days. ${ }^{14}$ Disinfection of surfaces commonly touched by people including light switches, elevator buttons, door handles, countertops, chair arms, should be done on regular basis. This will also help in reassuring the anxious health care workers.

Care should be taken to avoid putting health care professionals under too much burden and making sure they are given enough time to rest, provision of food and other necessities. A study done in a hospital of Wuhan in China with relation to COVID-19 showed that increased exhaustion at work possibly increases the risk of being infected with COVID-19. ${ }^{15}$

One hundred forty-one $(93.4 \%)$ participants were concerned about being exposed to COVID-19 at work. Choosing medical field as a profession, one knows the consequences they might face including high risk of exposure to contagious diseases. While health care professionals accept the responsibility to work in such an environment, they still have justified concern about the safety of their loved ones and family members at home. A recent study done in Pakistan showed 79.7 $\%$ doctors feared about infecting their family members during COVID-19 pandemic. ${ }^{16}$ In our study, $147(97.4 \%)$ participants had fear of taking the infection to loved ones at home.

Our study included participants from the public and private sector institutions in the city of Karachi, Pakistan. The findings do correlate with the presence of anxiety among health care professionals during a pandemic and certain factor playing a role in precipitating it. Due to rather new and early stages of this pandemic, there is insufficient data on similar published studies in Pakistan and hence comparison of different aspects of the results was rather difficult.

Limitations of the Study: There are certain limitations to the study, such as the healthcare professionals include doctors, along with nursing 
staff and the paramedical staff, but only doctors were being considered in this study. Another limitation in this study is we did not assess previous psychiatric illness in the participants prior to COVID-19, the reason to do so is because psychiatric illness is still considered a social taboo in our society, even amongst the medical community, and to ask questions regarding such could have led to false information by the participants and no available centralized medical record data about individuals having anxiety to confirm any information.

\section{CONCLUSION}

The study suggests that different grades of anxiety are present among doctors during pandemic COVID-19. Some contributory factors such as being female, healthcare workers dealing with suspected or confirmed cases may be associated with greater risk of having anxiety. Therefore, it is essential that the health care professionals are well taken care of not just physically but psychologically for them to be able to perform to their full potential. In doing so, certain guidelines and interventions are needed for the better care of the healthcare professionals.

Acknowledgement: We would like to thank and appreciate Dr. Asad Ullah Khalid, Dr. Osama bin Shakeel for their valuable assistance in analyzing data, and also Dr. Ayesha Saeed for assisting in data collection and literature search in this research study. We are forever grateful for their efforts.

\section{Financial Support: None.}

Conflicts of Interest: None.

\section{REFERENCES}

1. Huang $\mathrm{C}$, Wang $\mathrm{Y}, \mathrm{Li} \mathrm{X}$, Ren $\mathrm{L}$, Zhao J, Hu Y, et al. Clinical features of patients infected with 2019 novel coronavirus in Wuhan, China. Lancet (London, England) 2020;395(10223):497-506. doi: 10.1016/S01406736(20)30183-5

2. World Health Organization (2020). Coronavirus Disease 2019 (COVID-19). Situation Report - 202. Available online at: https://www.who.int/docs/default-source/ coronaviruse/ situation-reports / 20200420-sitrep-91covid-19.pdf?sfvrsn=fcf0670b_4 (Accessed August 10, 2020).

3. Pakistan latest victim of coronavirus. Available online at: https://www.geo.tv/latest/274482-pakistan-confirms-first (accessed March 7, 2020).

4. NDMA National Disaster Management Authority Pakistan. http://web.ndma.gov.pk/ Accessed on August 10, 2020.

5. Maunder R, Hunter J, Vincent L, Bennett J, Peladeau $\mathrm{N}$, Leszcz $\mathrm{M}$, et al. The immediate psychological and occupational impact of the 2003 SARS outbreak in a teaching hospital. Canadian Med Assoc J. 2003;168(10):1245-1251.
6. Spitzer RL, Kroenke K, Williams JB, Lowe B. A brief measure for assessing generalized anxiety disorder: the GAD-7. Arch Inter Med. 2006;166(10):1092-1097. doi: 10.1001/ archinte.166.10.1092

7. Lai J, Ma S, Wang Y, Cai Z, Hu J, Wei N, et al. Factors Associated With Mental Health Outcomes Among Health Care Workers Exposed to Coronavirus Disease 2019. JAMA Network Open. 2020;3(3):e203976. doi: 10.1001/ jamanetworkopen.2020.3976

8. Jordan P, Shedden-Mora MC, Lowe B. Psychometric analysis of the Generalized Anxiety Disorder scale (GAD7) in primary care using modern item response theory. PLoS One. 2017;12(8):e0182162. doi: 10.1371/journal. pone. 0182162

9. Ahmad S, Hussain S, Shah FS, Akhtar F. Urdu translation and validation of GAD-7: A screening and rating tool for anxiety symptoms in primary health care. JPMA. J Pak Med Assoc. 2017;67(10):1536-1540.

10. Tan BYQ, Chew NWS, Lee GKH, Jing M, Goh Y, Yeo LLL, et al. Psychological Impact of the COVID-19 Pandemic on Health Care Workers in Singapore. Ann Inter Med. [published online: April 06, 2020]. doi: 10.7326/M20-1083

11. Sethi BA, Sethi A, Ali S, Aamir HS. Impact of Coronavirus disease (COVID-19) pandemic on health professionals. Pak J Med Sci. 2020;36(COVID19-S4):COVID19-S6-S11. doi: 10.12669/pjms.36.COVID19-S4.2779

12. Kimball A, Hatfield KM, Arons M, James A, Taylor J, Spicer $\mathrm{K}$, et al. Asymptomatic and Presymptomatic SARS-CoV-2 Infections in Residents of a Long-Term Care Skilled Nursing Facility - King County, Washington, March 2020. MMWR. Morbidity and mortality weekly Report. 2020;69(13):377381. doi: $10.15585 /$ mmwr.mm6913e1

13. Adams JG, Walls RM. Supporting the Health Care Workforce During the COVID-19 Global Epidemic. JAMA [published online: March 12, 2020]. doi: 10.1001/jama.2020.3972

14. Ong SWX, Tan YK, Chia PY, Lee TH, Ng OT, Wong MSY, et al. Air, Surface Environmental, and Personal Protective Equipment Contamination by Severe Acute Respiratory Syndrome Coronavirus 2 (SARS-CoV-2) From a Symptomatic Patient. JAMA [published online: March 04, 2020]. doi: $10.1001 /$ jama.2020.3227

15. Ran L, Chen X, Wang Y, Wu W, Zhang L, Tan X. Risk Factors of Healthcare Workers with Corona Virus Disease 2019: A Retrospective Cohort Study in a Designated Hospital of Wuhan in China. Clinical infectious diseases: An Offic Public Infect Diseases Soc Am. [published online: March 17, 2020]. doi: $10.1093 / \mathrm{cid} / \mathrm{ciaa} 287$

16. Urooj U, Ansari A, Siraj A, Khan S, Tariq H. Expectations, Fears and Perceptions of doctors during COVID-19 Pandemic. Pak J Med Sci. 2020;36(COVID19-S4). doi: $10.12669 /$ pjms.36.COVID19-S4.2643

\section{Author's Contributions:}

SRH \& ZH: conceived the idea, contributed in writing the manuscript and are responsible for integrity of study.

MTJ, RKA, ZH: were involved in data collection. ZH: was involved in data interpretation and statistical analysis.

All the authors approved the final version and are accountable. 